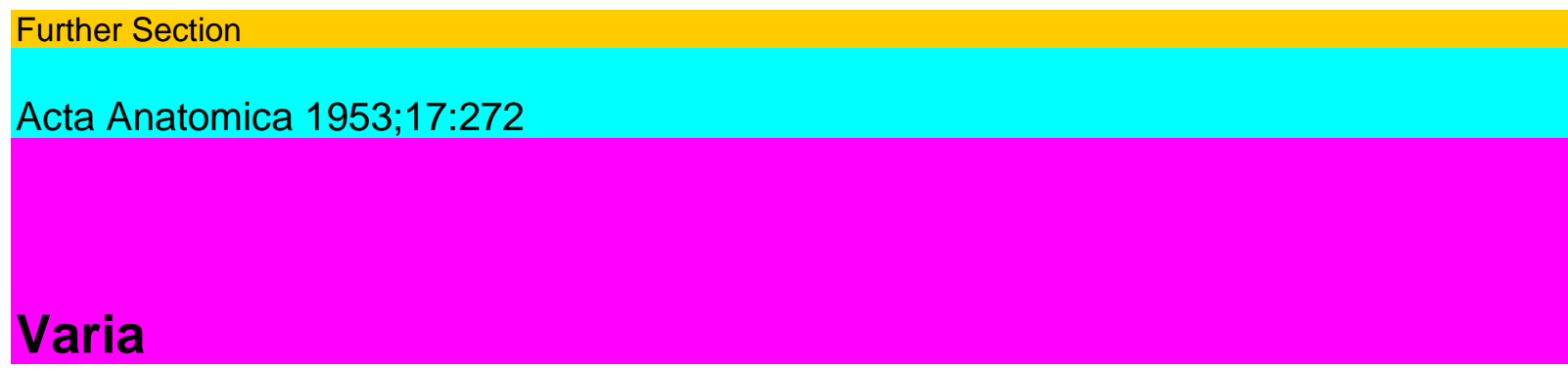

\title{
LETTER TO THE EDITOR Dear Sir,
}

In perusing the current literature with which this journal is concerned, we note that an ever increasing number of its articles deals with problems pertaining to research on "stress" and the so-called “adaptive hormones" (ACTH, STH, corticoids, adrenergic substances, etc.).

We are writing you because, in our opinion, the success of research in this complex and rapidly developing field largely depends upon the prompt availability and evaluation of relevant publications, a task for which we should like to solicit the assistance of your readers.

In 1950, our Institute has initiated the publication of a series of reference volumes entitled “Annual Reports on Stress" (Acta Medical Publishers, Montreal) in which the entire current world literature is surveyed every year (usually between 2000 and 4000 publications). Up to now, we had to compile the pertinent literature partly from medical periodicals, monographs, abstract journals and partly from reprints sent to us by the authors themselves. Of all these, reprints proved to be the best source of data which we felt deserved prompt attention in our annual reports. Hence, in the past, we have sent out several thousand individual reprint requests to authors of whom we knew that they are currently engaged in research on stress and allied topics. Even this procedure did not give us the wide coverage which would be desirable, because it is materially impossible to contact all these authors individually and it often takes too much time to get the requested reprints.

It is evident that in order to insure prompt inclusion of publications in the annual reports, these surveys must develop into a cooperative effort between the authors of original papers and the reviewers. This cooperation was greatly enhanced of late by the publication of announcements, in several medical journals, encouraging investigators interested in stress research to send us their reprints for this purpose as soon as they become available.

We should be grateful if by the publication of this note, you would also bring this problem to the attention of your readers.

We are Sir,

Very sincerely yours, Hans Selye, M.D., Ph.D., D.Sc, F.R.S. (C), Alexander Horava, M.D., Professor and Director of the Institute of Co-author of the "Annual Reports Experimental Medicine and Surgery. on Stress”. 